\title{
Application of Response Surface Methodology Coupled with Genetic Algorithm in the Optimization of Cutting Conditions for Surface Roughness in End-Milling of Inconel 718 Using Coated WC-Co Inserts
}

\author{
M. H. ISHTIYAQ ${ }^{1}$, A.K.M. Nurul AMIN, A.N.M. KARIM, Turnad L.G., M. Anayet U PATWARI \\ Department of Manufacturing and Material Engineering, International Islamic University, Malaysia (IIUM) \\ ${ }^{1}$ Corresponding author: i9610093@yahoo.com
}

\begin{abstract}
:
This paper presents an efficient method of optimisation of surface roughness in end milling of Inconel 718 using TiAlN coated inserts under dry conditions by coupling response surface methodology (RSM) with genetic algorithm (GA). RSM has been utilized to develop an efficient mathematical model for surface roughness in terms of cutting parameters. For this purpose, a number of machining experiments based on statistical central composite design of experiments method are carried out. Then the developed RS model is further interfaced with the GA to optimize the cutting conditions for achieving minimum surface roughness. GA improved the surface roughness by about $12 \%$.
\end{abstract}

Keywords: Surface roughness, Inconel 718, RSM model, Genetic Algorithm.

\section{Introduction}

Process modeling and optimization are two important issues in today's manufacturing. It is important, in metal cutting, to select the machining parameters to ensure high quality of machining products, reduce machining costs and increase machining efficiency.

Nowadays surface roughness and accuracy of product is getting greater attention in the industry. Surface roughness and dimensional accuracy have important bearing on performances of any machined part. Therefore, there is a need for predictions of these values. However number of surface roughness prediction models available in the literature is limited [1-5]. In order to establish an adequate functional relationship between the surface roughness and the cutting parameters (cutting speed, feed, and depth of cut), a large number of tests are needed for each and every combination of cutting tool and work piece materials. H. Oktem et al [1] performed a total of 243 experimental tests to develop a forth-order RS model for prediction of surface roughness of Aluminum alloy and then the developed model was coupled with GA to optimize the surface roughness. B. Ozcelik et al [2] generated 81 experimental data to develop a model by using Artificial Neural Networking (ANN) for predicting the surface finish of Inconel 718 in End Milling and then used the developed ANN model as a fitness function of GA to optimize the surface roughness. But the development of surface roughness prediction model increases the total number of tests and as a result the experimentation cost also increases.

Response Surface Methodology (RSM), as a group of mathematical and statistical techniques, is useful for modeling the relationship between the input parameters (cutting conditions) and the output variables. RSM saves cost and time by reducing the number of experiments required for modelling. RSM is a dynamic and foremost important tool of design of experiment (DOE), wherein the relationship between response(s) of a process with its input decision variables is mapped to achieve the objective of maximization or minimization of the response properties. Many machining researchers have used response surface methodology to design their experiments and assess results. Alauddin et al [3] applied response surface methodology to predict the surface finish in end milling of Inconel 718 considering cutting speed and feed as input parameters. S. Sharif et al [4] developed a predicted model for surface roughness when end milling titanium alloy (Ti-6Al-4V) using uncoated carbide under flooded condition. P. V. S. Suresh et al [5] used response surface methodology in predicting surface roughness of mild steel in turning and applied a GA approach for optimization.

In the present work, an effort has been made to estimate the surface roughness values in end milling of Inconel 718 using RSM. It has also been attempted to optimize the surface roughness prediction model using a GA approach.

\section{Materials and Methods}

In this work, experimental results were used for modelling using RSM. The RSM is practical, economical and relatively easy for use and it was used by a large number of researchers for modelling machining processes [3-6]. The experimental data was utilized to build mathematical models (first-order and second-order) applying regression method. This mathematical model was taken as objective function and was optimized using a Genetic Algorithm approach to obtain the machining conditions for the required surface finish. 


\subsection{RSM Mathematical Model}

RSM [6] is a collection of mathematical and statistical techniques that are useful for modelling and analysing problems in which response of interest is influenced by several variables, and the objective is to obtain the response.

The following linear relationship could be considered for achieving this:

$\mathrm{y}=f(v, a, f)+\varepsilon$

Where $v, a, f$ are speed, axial depth of cut and feed respectively of the machining processes, and $\varepsilon$ is experimental error.

Let $f(v, a, f)=\eta$

The surface represented by ' $\eta$ ' is called response surface.

The relationship between surface roughness and other independent variables is modelled as follows:

$$
R_{a}=C v^{k} a^{l} f^{m}
$$

Where ' $C$ ' is a model constant and $\mathrm{k}, 1$ and $\mathrm{m}$ are model parameters. The above equation (1) can be represented in linear mathematical form as follows

$$
\ln \left(R_{a}\right)=\ln C+k \ln v+l \ln a+m \ln f
$$

The first-order linear model of the above equation (2) can be represented as follows

$$
\hat{y}_{1}=y-\varepsilon=b_{0} x_{0}+b_{1} x_{1}+b_{2} x_{2}+b_{3} x_{3}
$$

Where, $\hat{\mathrm{y}}$ is the estimated response based on first-order equation and $\mathrm{y}$ the measured surface roughness on a logarithmic scale, $x_{0}=1$ (dummy variable), $x_{1}, x_{2}, x_{3}$ are logarithmic transformations of speed, depth of cut and feed respectively, while $b_{0}, b_{1}, b_{2}$, and $b_{3}$ are the parameters to be estimated, $\varepsilon$ the experimental error.

The second-order model can be extended from the first-order model's equation as follows

$$
\begin{aligned}
& \hat{y}_{2}=y-\varepsilon=b_{0} x_{0}+b_{1} x_{1}+b_{2} x_{2}+b_{3} x_{3}+b_{11} x_{1}^{2}+b_{22} x_{2}^{2} \\
& +b_{33} x_{3}^{2}+b_{12} x_{1} x_{2}+b_{13} x_{1} x_{3}+b_{23} x_{2} x_{3}
\end{aligned}
$$

Where $\hat{\mathrm{y}}_{2}$ is the estimated response based on the secondorder model. Analysis of variance (ANOVA) is used to verify and validate the model.

\subsection{Optimization by Genetic Algorithms}

Genetic Algorithms are search algorithms for optimisation, based on the mechanics of natural selection and genetics [7]. The mechanics of GA is simple, involving copying of binary strings and the swapping of the binary strings. The simplicity of operation and computational efficiency are the two main attractions of the GA approach. The GA solves optimization problem iteratively based on biological evolution process in nature (Darwin's theory of survival of the fittest) [7].

The optimization problem in this study is solved by coupling the developed RSM model with the developed GA as shown in Fig. 1. In the solution procedure of an optimization problem with GA begins with a set of parameter values or "chromosomes" (usually in the form of bit strings) which are randomly generated or selected. The entire set of these chromosomes comprises a "population". The chromosomes evolve during several iterations or "generations". New generations called "offspring" are generated using the "crossover" and "mutation" technique. Crossover involves splitting two chromosomes and then combining one-half of each chromosome with the other pair. Mutation involves flipping a single bit of a chromosome. The chromosomes

\begin{tabular}{|c|c|c|}
\hline $\begin{array}{l}\text { Experimental } \\
\text { Measurements }\end{array}$ & $\begin{array}{l}\text { RSM } \\
\text { Model }\end{array}$ & $\begin{array}{l}\text { Genetic } \\
\text { Algorithm }\end{array}$ \\
\hline
\end{tabular}
are then "evaluated" using certain "fitness" criteria and the best ones are kept while the others are discarded. This process repeats until one chromosome has the best fitness and is taken as the best solution of the problem.

Figure 1: Interaction of experimental measurements, RSM model and GA during surface roughness optimisation.

GA is very appealing for single and multi-objective optimisation problems. Some of its advantages are as follows: (1) as it is not based on gradient-based information, it does not require the continuity of convexity of the design space, (2) it can explore large search space and its search direction or transition rule is probabilistic, not deterministic, in nature, and hence, the chance of avoiding local optimality is more, (3) it works with a population of solution points rather than a single solution point as in conventional techniques, and provides multiple near-optimal solutions, (4) it has the ability to solve convex, and multi-model function, multiple objectives and non-linear response function problems, and it may be applied to both discrete and continuous objectives functions [8].

\section{Experimental details}

In this study, cutting tests are carried out for End milling in dry conditions on Vertical Machining Centre (VMC ZPS, Model: MLR 542) with $20 \mathrm{~mm}$ diameter end-mill tool holder fitted with a single TiAlN coated carbide insert. Machining was performed with quarter immersion cutting (radial depth of cut is $5 \mathrm{~mm}$ ). The surface roughness of Inconel 718 was measured by Mitutoyo SURFTEST SV-500.

In this work, down milling method was employed in end milling process due to some advantages such as better surface finish, less heat generation, larger tool life, better geometrical accuracy and compressive stresses favourable for carbide edges [9].

\subsection{Cutting Conditions}

Cutting conditions is chosen by an appropriate selection of cutting parameter values corresponding to cutting speed, axial depth of cut, feed within specific ranges. Sampling within the ranges is performed using statistical experimental design technique, the five-level 
small CCD design. The independent variables were then coded to the levels using the following transformations

$$
x=\frac{\ln x_{n}-\ln x_{n 0}}{\ln x_{n 1}-\ln x_{n 0}}
$$

Where $\mathrm{x}$ is the coded value of any factor corresponding to its natural value $\mathrm{x}_{\mathrm{n}} . \mathrm{x}_{\mathrm{n} 1}$ is the +1 level and $\mathrm{x}_{\mathrm{n} 0}$ is the natural value of the factor corresponding to the base of zero level.

The levels of independent variables and coding identifications are presented in Table 1.

\subsection{Cutting Tool}

TiAlN coated Cutting tool ML2030 of type CoroMill 390 end mill was selected from the Sandvik Coromant tool catalogue [10] to machine Inconel 718. Tool wear is not considered as the criteria influencing the result of cutting process. To satisfy this criterion, the tool being utilized was replaced with a new one when average flank wear reaches $0.15 \mathrm{~mm}$. Wear measurement was taken by using an optical microscope with a maximum value of 10 times magnification.

Table 1: Level of Independent Variables and Coding Identification.

\begin{tabular}{|c|c|c|c|c|c|}
\hline Levels & Lowest & Low & Centre & High & Highest \\
\hline Coding & $-\sqrt{2}$ & -1 & 0 & +1 & $+\sqrt{ } 2$ \\
\hline $\begin{array}{c}\mathrm{x}_{1} \text { speed, } v \\
(\mathrm{~m} / \mathrm{min})\end{array}$ & 20.31 & 23.8 & 34.94 & 51.3 & 60 \\
\hline $\begin{array}{c}\mathrm{x}_{2}, \text { axial DOC, } \\
a(\mathrm{~mm})\end{array}$ & 0.108 & 0.15 & 0.331 & 0.73 & 1.013 \\
\hline $\begin{array}{c}\mathrm{x}_{3}, \text { feed, } f \\
(\mathrm{~mm} / \mathrm{tooth})\end{array}$ & 0.012 & 0.015 & 0.025 & 0.041 & 0.05 \\
\hline
\end{tabular}

\subsection{Workpiece Material}

Cutting experiments were carried out in a block of Inconel 718. The workpiece material was clamped onto the machine table to provide maximum rigidity. The Workpiece initial dimensions were $279.4 \mathrm{~mm}$ (length) $\times$ $228 \mathrm{~mm}$ (width) $\times 50.8 \mathrm{~mm}$ (height). The chemical and mechanical properties are given in Table 2.

Table 2: Chemical and Mechanical Properties of Inconel 718

\begin{tabular}{|c|c|c|c|c|c|c|}
\hline \multicolumn{7}{|c|}{ Chemical composition in percentage } \\
\hline Component & $\mathrm{C}$ & $\mathrm{Mn}$ & $\mathrm{Si}$ & $\mathrm{F}$ & $\mathrm{Ni}$ & $\mathrm{Al}$ \\
\hline Wt percentage & 0.034 & 0.03 & 0.13 & 19.4 & 51.88 & 0.54 \\
\hline Component & $\mathrm{Co}$ & $\mathrm{Mo}$ & $\mathrm{Cr}$ & $\mathrm{Cu}$ & $\mathrm{Ti}$ & $\mathrm{Nb}+\mathrm{Ta}$ \\
\hline Wt percentage & 0.03 & 3.03 & 18.38 & 0.07 & 1.0 & 5.2 \\
\hline \multicolumn{7}{|c|}{ Mechanical properties } \\
\hline $\begin{array}{c}\text { Tensile } \\
\text { strength(MPa) }\end{array}$ & $\begin{array}{r}\text { Yield strength } \\
(\mathrm{MPa})\end{array}$ & \multicolumn{3}{c|}{$\begin{array}{c}\text { Elongation } \\
(\%)\end{array}$} & $\begin{array}{c}\text { Hardness } \\
\text { (HRC) }\end{array}$ \\
\hline 1380 & 1130 & \multicolumn{7}{c|}{20} & 36 \\
\hline
\end{tabular}

\subsection{Experimental Design}

In the experiment, small central composite design (CCD) was used to develop the first order and second order model. The analysis of mathematical models was carried out using Design Expert 6.0 package for both the first and second order models. Cutting condition and the surface roughness values obtained is presented in Table 3.

\section{Results and Discussion}

\subsection{Development of first order Model Using CCD} Design

Using the experimental results in Table 3, the cutting force prediction model was formulated as

$$
\hat{y}_{1}=-2.20+0.29 x_{1}+0.24 x_{2}-0.17 x_{3}
$$

By substituting the values of $x_{i}$ from Equation (5) into Equation (7) the following equation for $\mathrm{R}_{\mathrm{a}}$ is generated:

$$
R_{a}=0.00293 v^{0.755} a^{0.303} f^{-0.344}
$$

Table 3: Experimental Results with cutting conditions in coded factors for small CCD Model.

\begin{tabular}{|c|c|c|c|c|c|}
\hline $\begin{array}{c}\text { Standard } \\
\text { Order }\end{array}$ & Type & $\begin{array}{c}\mathrm{x}_{1} \\
(\mathrm{~m} / \mathrm{min})\end{array}$ & $\begin{array}{c}\mathrm{x}_{2} \\
a \\
(\mathrm{~mm})\end{array}$ & $\begin{array}{c}\mathrm{x}_{3} \\
f \\
(\mathrm{~mm} / \text { tooth })\end{array}$ & $\begin{array}{c}\text { Surface } \\
\text { Roughness } \\
\mathrm{R}_{\mathrm{a},}(\mu \mathrm{m})\end{array}$ \\
\hline 1 & Factorial & 1 & 1 & -1 & 0.27 \\
\hline 2 & Factorial & 1 & -1 & 1 & 0.09 \\
\hline 3 & Factorial & -1 & 1 & 1 & 0.07 \\
\hline 4 & Factorial & -1 & -1 & -1 & 0.067 \\
\hline 5 & Centre & 0 & 0 & 0 & 0.082 \\
\hline 6 & Centre & 0 & 0 & 0 & 0.085 \\
\hline 7 & Centre & 0 & 0 & 0 & 0.081 \\
\hline 8 & Centre & 0 & 0 & 0 & 0.087 \\
\hline 9 & Centre & 0 & 0 & 0 & 0.078 \\
\hline 10 & Axial & -1.4142 & 0 & 0 & 0.075 \\
\hline 11 & Axial & 1.4142 & 0 & 0 & 0.12 \\
\hline 12 & Axial & 0 & -1.414 & 0 & 0.09 \\
\hline 13 & Axial & 0 & 1.414 & 0 & 0.16 \\
\hline 14 & Axial & 0 & 0 & -1.4142 & 0.24 \\
\hline 15 & Axial & 0 & 0 & 1.4142 & 0.195 \\
\hline
\end{tabular}

The analysis of variance (ANOVA) of linear CCD is summed up in Table 4. From the Table, the "F-Value" of Model is found to be 4.37, which implies that the model is significant. There is only $3.28 \%$ chance that the "FValue" could occur due to noise. The lack of fit value of 95.85 implies the LOF is significant. There is only a $0.03 \%$ chance that a "Lack of Fit F-value" this large occur due to noise. Therefore, the model cannot be used to predict surface roughness values generated by the linear CCD model. From the ANOVA analysis we can affirm that the linear CCD model was not adequate to predict the surface roughness values close to the experimental results.

\subsection{Development of Second-order Model Using CCD Design}


The second order model using CCD design was postulated to extend the variables range in obtaining the relationship between the surface roughness and the machining independent variables. The model was based on the centre composite design with added augment points to the nucleus of the design. The distance of the axial points was 1.4142 units. Fit and summary test in Table 4 summarises that the quadratic model CCD model was more significant than linear model and it also proved that linear model has a significant lack of fit (LOF). Therefore, the quadratic model was chosen in order to develop the CCD model.

Table 4: ANOVA of linear CCD Model
\begin{tabular}{|c|c|c|c|c|c|c|}
\hline & SS & DF & MS & $\begin{array}{c}\text { F } \\
\text { Value }\end{array}$ & Prob > F & \\
\hline Source & & & & & & \\
\hline Block & 0.55 & 1 & 0.55 & & & significant \\
\hline Model & 1.37 & 3 & 0.46 & 4.37 & 0.0328 & \\
\hline A & 0.67 & 1 & 0.67 & 6.37 & 0.0302 & \\
\hline B & 0.48 & 1 & 0.48 & 4.57 & 0.0583 & \\
\hline C & 0.23 & 1 & 0.23 & 2.17 & 0.1714 & \\
\hline Residual & 1.05 & 10 & 0.10 & & & \\
\hline $\begin{array}{c}\text { Lack of } \\
\text { Fit }\end{array}$ & 1.04 & 6 & 0.17 & 95.85 & 0.0003 & significant \\
\hline $\begin{array}{c}\text { Pure Error } \\
\text { Cor Total }\end{array}$ & 0.007 .23 & 4 & 0.0018 & & & \\
\hline Con & 14 & & & & \\
\hline
\end{tabular}

Using the experimental data in Table 3 The second order model in coded forms was found as:

$$
\begin{aligned}
& \hat{y}=-2.31+0.17 x_{1}+0.2 x_{2}-0.073 x_{3}-0.1 x_{1}^{2} \\
& +0.31 x_{3}^{2}+0.19 x_{1} x_{2}-0.082 x_{1} x_{3}-0.25 x_{2} x_{3}
\end{aligned}
$$

The model term $\mathrm{x}_{2}{ }^{2}$ was insignificant because probability F-value of that term was 0.3663 which is more than 0.0500 . Therefore, that model term (i.e. $\mathrm{x}_{2}{ }^{2}$ ) was reduced to improve the model. For this second-order CCD model the experimental error $\varepsilon$ was found to be -0.17328 .

To verify the adequacy of the proposed second order CCD model, ANOVA was used and the results are shown in the table 5, the Model F-value of 165.47 implies the model is significant. There is only a $0.01 \%$ chance that this large value of "F-Value" of the model could occur due to noise. The lack of fit "F-Value" of 1.04 implies that the Lack of Fit is not significant relative to the pure error. There is a $36.63 \%$ chance that a "Lack of Fit FValue" this large could occur due to noise. Therefore, this model is adequate to predict the surface roughness values. We can now use the model to navigate the response surface.
Figure 2 shows the contours of experimental results and predicted surface roughness values generated by the linear and quadratic CCD model. From the Fig. 2 we can affirm that the quadratic CCD model is adequate to predict the surface roughness values closer to the experimental results.

Table 5: ANOVA for second order CCD model

\begin{tabular}{|c|c|c|c|c|c|l|}
\hline & SS & DF & MS & $\begin{array}{c}\text { F } \\
\text { Value }\end{array}$ & Prob > F & \\
\hline Source & & & & & & \\
\hline Block & 0.55 & 1 & 0.55 & & & Significant \\
\hline Model & 2.41 & 8 & 0.30 & 165.47 & $<0.0001$ & \\
\hline A & 0.11 & 1 & 0.11 & 60.67 & 0.0006 & \\
\hline B & 0.17 & 1 & 0.17 & 90.92 & 0.0002 & \\
\hline C & 0.022 & 1 & 0.022 & 11.84 & 0.0184 & \\
\hline A & 0.079 & 1 & 0.079 & 43.61 & 0.0012 & \\
\hline C & 0.72 & 1 & 0.72 & 396.10 & $<0.0001$ & \\
\hline AB & 0.072 & 1 & 0.072 & 39.78 & 0.0015 & \\
\hline AC & 0.014 & 1 & 0.014 & 7.42 & 0.0416 & \\
\hline BC & 0.12 & 1 & 0.12 & 65.99 & 0.0005 & \\
\hline Residual & 0.009103 & 5 & 0.001821 & & & \\
\hline $\begin{array}{c}\text { Lack of } \\
\text { Fit }\end{array}$ & 0.001873 & 1 & 0.001873 & 1.04 & 0.3663 & significant \\
\hline Pure Error & 0.007230 & 4 & 0.001808 & & & \\
\hline Cor Total & 2.97 & 14 & & & & \\
\hline
\end{tabular}

Figure 3 shows the surface roughness values for actual surface roughness values verses the predicted one of second-order quadratic CCD model. From Fig. 3 it can be confirmed that the quadratic CCD model very efficiently predict the surface roughness values in the range of the cutting parameters. So the developed quadratic CCD model now can be used to optimise the cutting parameters for best surface roughness in the range by applying genetic algorithm (GA).

\subsection{Optimization problem formulation}

The objective of the optimisation is to achieve the minimum possible surface roughness value. This can be achieved efficiently by adjusting cutting conditions with the help of an appropriate numerical optimization method. For this, minimization of surface roughness problem must be formulated in the standard mathematical format as below:

Find: $v, a, f$

Minimize: $\operatorname{Ra}(v, a, f)$

Subject of constrains: $R_{a} \leq 0.067 \mu \mathrm{m}$.

Within ranges:

$23.8 \leq v \leq 51.3$

$0.15 \leq a \leq 0.73$

$0.015 \leq f \leq 0.041$ 


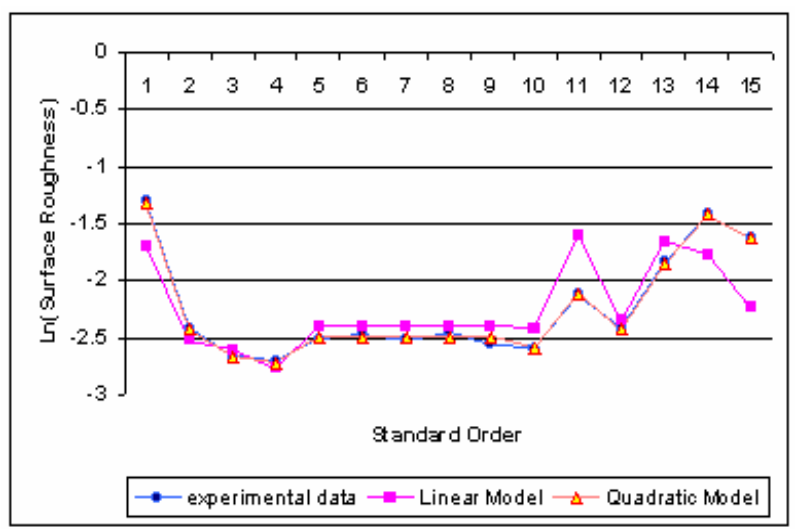

Figure 2: Surface roughness contours of experimental values and predicted values of linear and quadratic CCD model

In Equation (9b), Ra is the quadratic CCD RSM model developed in this work. The independent variables $v, a, f$ are the cutting parameters. The ranges of cutting parameters in optimization have been selected based on the ranges of the RSM model. In the optimization problem definition above, a better solution is also forced through the constraint definition. Constraint definition searches a surface roughness value $\left(R_{a}\right)$, which is less than the lowest value in 15 data sets in Table 3 if possible. Here in Table 3 the minimum surface roughness value in 15 data sets is $0.067 \mu \mathrm{m}$.

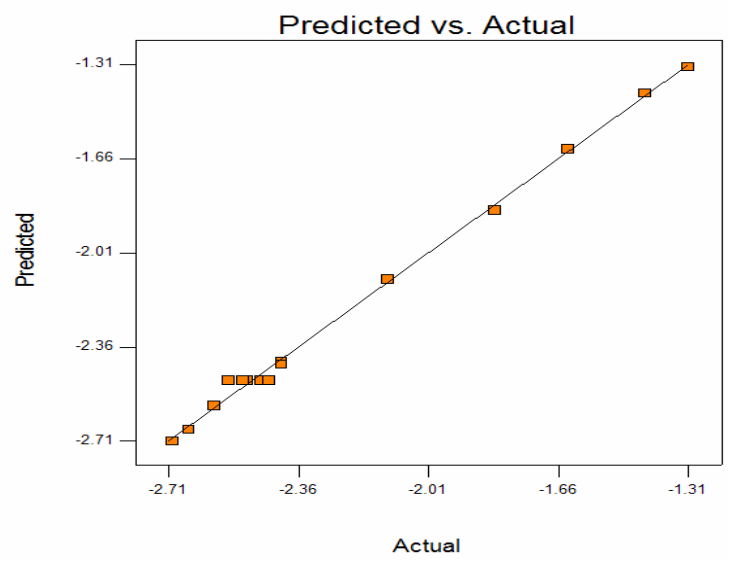

Figure 3: Actual values vs. Predicted values for $\operatorname{Ln}(\mathrm{Ra})$ for second-order quadratic CCD model.

\subsection{Optimising by Genetic Algorithm}

In this work, MATLAB 7.0 Toolbox for GA is used to develop the GA program [11]. The critical parameters in GA are the size of the population, mutation, number of generation (i.e. generations), etc. and their values are given in Table 6. The developed quadratic CCD model is used as a fitness function for the GA. The GA program written in MATLAB programming language selects chromosomes based on the objective value and the level of constraint violation.

Table 6: GA parameters

\begin{tabular}{|c|c|}
\hline Subject & Values \\
\hline Population size & 50 \\
\hline Scaling function & Rank \\
\hline Selection of function for mating & Stochastic uniform \\
\hline Crossover function & Scattered \\
\hline Crossover fraction & 0.8 \\
\hline Mutation & Gaussian \\
Function & 1.0 \\
Scale & 1.0 \\
Shrink & \\
\hline Stopping criteria & 300 \\
Generation & \\
\hline
\end{tabular}

\subsection{Optimisation results and discussion}

By solving the optimisation problem, the GA reduces the surface roughness from $0.067 \mu \mathrm{m}$ to $0.059 \mu \mathrm{m}$ by about $12 \%$ compared to the initial cutting condition. The best (optimum) cutting condition leading to the minimum surface roughness is shown in Table 7 . The predicted optimum cutting condition by GA is further validated with a physical measurement. Predicted surface roughness value is compared with the measurement and difference was found to be less than $2.1 \%$. So it is affirmed that GA result agrees very well with the measurement.

Table 7: The best cutting condition found in GA

\begin{tabular}{|l|l|}
\hline Parameters & After optimisation \\
\hline Cutting condition & \\
$V(\mathrm{~m} / \mathrm{min})$ & 23.81 \\
$a(\mathrm{~mm})$ & 0.1501 \\
$f(\mathrm{~mm} /$ tooth $)$ & 0.02041 \\
\hline Response & Results \\
\hline Surface roughness $(\mu \mathrm{m})$ & \\
GA & 0.059 \\
Measurement & 0.0578 \\
\hline
\end{tabular}

\section{Conclusions}

In this study, a second-order quadratic CCD model was developed using RSM for predicting surface roughness values in end-milling of Inconel 718. In generating the model statistical RSM was utilized. The developed RSM model was further coupled with a developed GA to find the optimum cutting condition 
leading to the least surface roughness value. GA improved the surface roughness by about $12 \%$. The predicted optimum cutting condition was verified with an experimental measurement. It was found that GA prediction correlates successfully with the experimental results. Difference was found to be less than $2.1 \%$. This ascertains that the optimization methodology proposed in this study by coupling the developed RSM model and the developed GA is effective and can be utilized in other machining problems such as tool life, cutting force, vibration and chatter etc. as well.

\section{Acknowledgement}

The authors wish to thank the Research Centre IIUM and the Ministry of Science, Technology and Innovation Malaysia for their financial support to the above project through the E-Science funding (Project No. 03-01-08SF0001) and FRGS fund Project (Project No. 0106-23).

\section{Reference}

[1] H. Oktem, T. Erzurumlu, H. Kurtaran, Application of response surface methodology in the optimization of cutting conditions for surface roughness, 2005, Journal of Material Processing Technology, 170 (2005) 11-16.

[2] B. Ozcelik, H. Oktem, H. Kurtaran, Optimum surface roughness in end milling Inconel 718 by coupling neural network model and genetic algorithm, 2005, Int. J. Adv. Manuf. Tehnol. (2005) 27: 234-241.

[3] M. Alauddin, M. A. El Baradie, M.S.J. Hashmi, Optimization of Surface Finish in End Milling Inconel 718, 1996, Journal of Materials Processing Technology 56 (1996) 54-65.

[4] S. Sharif, A.S. Mohruni, M.Y. Noordin, V.C. Venkatesh, Optimization of Surface Roughness Prediction Model in End Milling Titanium Alloy (Ti-6Al4V), 2006, International Conference on Manufacturing Science and Technology, Malaka, Malaysia, August 28-30,2006.

[5] P. V. S. Suresh, P. Vekateswara Rao, S. G. Deshmukh, A Genetic Algorithm Approach for Optimization of Surface Roughness Prediction Model, International Journal of Machine Tools \& Manufacture 42 (2002) 675-680.

[6] D. C. Montgomery, Design and Analysis of Experiments, $2^{\text {nd }}$ ed., John Wiley, New York, 1984.

[7] Randy L. Haupt, Practical Genetic Algorithms, John Wiley, New York, 1998.

[8] Indrajit Mukherjee, Pradip Kumar Ray, A review of optimization techniques in metal cutting processes, 2006, Computers \& Industrial Engineering 50 (2006) 15-34

[9] H. Z. Li, H. Zeng, X. Q. Chen, An experimental study of tool wear and cutting force variation in the end milling of Inconel 718 with coated carbide inserts,2006, Journal of Materials Processing Technology, 180 (2006) 296-304.
[10] Sandvik coromate, 2006, tool catalog. Sandvik Coromant, Sandviken, Sweden.

[11] MathWorks Incorporation (2006) MATLAB user manual version 7.0 R14. MathWorks Incorporation, Natick, MA. 